\title{
Screening of New Born Babies for Thyroid Stimulating Hormone, Glucose-6-Phosphate Dehydrogenase, 17- Hydroxyprogesterone and Sickle Cell Disease
}

\author{
Mukunda Raj Kalouni ${ }^{*}$, Z. G. Badade², Nimain Mohanty ${ }^{3}$, Bhup Dev Bhatta ${ }^{4}$,Bhupendra R \\ Pandey ${ }^{5}$, Rajendra Dev Bhatt ${ }^{6}$
}

BACKGROUND: The expanded newborn screening programme has now initiated worldwide. Many of the countries around the world made this programme mandatory. The effect of such screening system gives the advantage or betterment to the society as well as the nation.

METHODS: Samples were collected from babies aged 48-72 hours by heel prick method in a filter paper provided by Bio-Rad. The written consent was taken from the parents before collecting the blood samples. Blood samples were assayed for TSH and17-OHP by Enzyme Immuno Assay (EIA), G-6-PD was estimated by colorimetric assay provided by Bio-Rad Laboratories, USA and Sickle Cell Disease by sickling test

RESULTS: A total of 715 newborns were screened for TSH, G-6-PD, 17-OHP and Sickle cell disease. Out of which 1 neonate found abnormal (increased) thyroid stimulating hormone (1/715), and 8 neonates were G-6-PD deficient (8/715). We did not find any cases of congenital adrenal hyperplasia and sickle cell disease.

CONCLUSION: In this study the prevalence of Congenital Hypothyroidism and Glucose-6Phosphate dehydrogenase deficiency was found to be 1:715 and 1:89 respectively. No cases of congenital adrenal hyperplasia and sickle cell disease were found.

KEYWORDS: Thyroid stimulating hormone, 17hydroxyprogesterone, Glucose-6 phosphate dehydrogenase, sickle cell, new born screening.

(C) 2015 Nepalese Association for Clinical Chemistry

\section{Introduction}

The term 'newborn screening' is used to describe various types of tests that are done during the first few days of a newborn's life. Screening separates those who might have the disorder from those who probably do not have the disorder. Newborn screening that properly timed and performed has the potential for preventing catastrophic health outcome, including death [1]

Newborn screening (NBS) popularly known as neonatal screening is testing newborn babies for serious developmental, genetic and metabolic disorders so that timely preventive action can be taken before the critical symptoms or sequele such as mental and/or motor retardation, physical disabilities or even death occurs. The prompt detection therefore requires vigilance and the early \& presymptomatic measurement of biochemical markers. Their early, presymptomatic detection is significant as timely intervention, treatment and therapy can lead to reductions of morbidity, mortality and associated disabilities in affected infants, thus giving baby the best chance of healthy life [2].

New born screening is not carried out routinely due to early discharge of neonates and high screening costs. People generally stay far away from the maternity facility, some rural areas lack a well organised health programme and the identification of the recalled babies is not always as rapid as it should be. It has been stated that the collection of the newborn blood specimens for screening should be performed before nursery discharge. The committee of genetics of the American Academy of Paediatrics (AAP) insists on collecting the blood specimen for screening before nursery discharge regardless of when discharge occurs. In the case of discharge before 24 hours a second specimen is recommended [3].

Hence the present study was designed with the objective to screen the newborn babies for thyroid stimulating hormone, 17hydroxyprogesterone, Glucose-6-phosphate dehydrogenase and Sickle cell disease from Navi Mumbai and Raighad District.

The district is inhabited by a sizable tribal

'Department of Clinical Pathology, Manipal Teaching Hospital, Pokhara, Nepal. ${ }^{2}$ Department of Biochemistry, MGM Medical College, Navi Mumbai, India. ${ }^{3}$ Department of Paediatrics, MGM Medical College, Navi Mumbai, India. ${ }^{4}$ Department of Biochemistry, Manipal Teaching Hospital, Pokhara, Nepal. ${ }^{5}$ Department of Biochemistry, United Reference Laboratory, Pokhara, Nepal. ${ }^{\circ}$ Department of Biochemistry, KUSMS, Dhulikhel Hospital, Dhulikhel, Nepal. 
population also. It was thought worthwhile to access the extent of the problems in this area where such screening program is conspicuous by its absence so far.

\section{Methods}

The present study was carried out in the department of Biochemistry, Department of paediatrics, MGM Medical College, and MGM Group of Hospitals, Kamothe, Kalamboli, Vashi, CBD, Navi Mumbai. Newborns admitted in the NICU and Post-natal wards during the period of January 2012 to March 2013 were enrolled in the study. Total 715 newborns of aged between 48-72 hours were screened. The institutional ethical clearance was obtained from ethical committee, MGM Medical College, Navi Mumbai.

Blood sample were collected in to Schleicher and Schell (S\&S) 903 specimen collection paper and small of blood sample was collected by capillary tube in to the EDTA (ethylene diamine tetra acetic acid) vial. Blood sample collected on filter paper were dried and estimation of thyroid stimulating hormone and 17hydroxyprogesterone by Enzyme-Immunoassay (EIA) provided by Bio-Rad laboratories. Glucose6-phosphate dehydrogenase were estimated quantitatively by colorimetric assay [4] Sickle cell were detected by sickling test [5]

Written consent was obtained from all the parents.

\section{Results}

The present study includes total 715 newborns, out of which 371 were males and 344 were females having percentage 51.88 and 48.12 respectively.

\begin{tabular}{lcc}
\multicolumn{3}{l}{ Table 1: Gender-wise distribution of } \\
\hline Newborns screened & $\mathrm{N}$ & $\mathbf{\%}$ \\
\hline Male & 371 & 51.88 \\
Female & 344 & 48.12 \\
Total & 715 & 100 \\
\hline
\end{tabular}

We found prevalence of congenital hypothyroidism and glucose-6-phosphate dehydrogenase deficiency $0.13 \%$ and $1.11 \%$ respectively. Total 715 newborns were screened for congenital hypothyroidism by estimating the TSH. Out of which 1 neonate reported abnormal thyroid function whose TSH was found to be elevated. Confirmation was done after two weeks by further determination of thyroid function test.
Decreased T4 was observed. The baby was referred to paediatric endocrinology clinic MGM Hospital.

Table 2. Prevalence of congenital hypothyroidism, congenital adrenal hyperplasia, Glucose-6-phosphate dehydrogenase and sickle cell disease in newborn babies.

\begin{tabular}{lcc}
\hline Parameters & Positive & Prevalence \\
\hline TSH & 1 & $1: 715$ \\
17-OHP & 0 & 0 \\
G-6-PD & 8 & $1: 89$ \\
Sickle cell test & 0 & 0 \\
\hline
\end{tabular}

Any positive case of congenital adrenal hyperplasia and sickle cell disease was not observed. Hence, prevalence of congenital adrenal hyperplasia and sickle cell disease is very less in Navi Mumbai and Raighad district.

\section{Discussion}

Newborn screening is the process by which infants are screened shortly after the birth of a child in order to detect whether the child suffers from a congenital disease or metabolic disorder. The importance of screening is to detect the disorder early and to reduce infant mortality rate [2].

The screening of newborns for various disorders identifies presymptomatically and provides the opportunity to improve the life of affected children and their families. A well-established newborn screening infrastructure provides the opportunity to expand case detection to other serious conditions, thus increasing the potential for saving lives, preventing mental retardation, preventing physical disabilities, and improving the health and well-being of society.

\section{THYROID STIMULATING HORMONE}

In our study, incidence of congenital hypothyroidism is $1 / 715$ ( 1 in 715) which is close to incidence of Pakistan 1 in 1000 [6]. Variation in the level of TSH may be due the difference in the iodine levels or it may be due to genetic variation. Globally, the prevalence of Congenital Hypothyroidism approaches 1:3000, with substantially higher prevalence in iodine deficient areas, sometimes in excess of 1:900 [7]. Studies in the UK [8] and South Africa [9] observed that $\mathrm{CH}$ appears to be several times more prevalent in children of Asian (including Indian) ancestry; however, a recent study in India indicates a prevalence of approximately 1:2630 among people there. Studies have also found a higher prevalence (approximately 2:1) of $\mathrm{CH}$ among females. Newborn screening in Andhra Pradesh revealed a high frequency of inborn errors of metabolism (1/1000). In the study conducted in 
18,300 neonates, it was reported that Congenital Hypothyroidism is the most common disorder (1in 1,700) followed by CAH ( 1 in 2,575) [10].

\section{GLUCOSE-6-PHOSPHATE DEHYDROGENASE}

G-6-PDD is most common enzyme deficiency affecting 400 million people worldwide. In India, exact incidence of G-6-PDD is not known. However, it has been reported to vary with ethnicity from less than $1-28 \%$ [10]. There has been no precise previous information about the incidence of G-6-PD deficiency in neonates in Navi Mumbai and Raigad population.

Our study suggests that the prevalence of G-6-PD was found to be $1.11 \%$ which is closer to the $2 \%$ prevalence in Saudi Arabia reported by Niazi et al [11] but lower than the studies by al-Nuaim et al [12] in the Riyadh and Zaki et al [13] in the Qatif and Al Hasa. In our study we found that higher prevalence of Glucose-6-phosphate dehydrogenase in males $1.61 \%$ and in females $0.58 \%$. The ratio of male and female for Glucose6-phosphate dehydrogenase was found 3:1.

\section{7-HYDROXYPROGESTERONE}

In our study none of the cases were found positive for 17-hydroxyprogesterone i.e., none of the newborn babies had congenital adrenal hyperplasia. A sample survey from South India revealed incidence to be 1: 2575 . It is an underdiagnosed condition in India with frequency ranging from $1.4 \%$ to $38 \%$ [2].

Another study from Chandigarh shows the prevalence of congenital adrenal hyperplasia was 1 in 6813 [10].

The prevalence of CAH observed in the USA was 1:15 981, in Japan 1:19 111 and in Europe $1: 14970$. The highest prevalence of CAH has been found in two geographically isolated populations, the Yupik Eskimos of Western Alaska (1:282) and the French island of $\mathrm{La}$ Re'union in the Indian Ocean (1:6071) [14].

Another congenital adrenal hyperplasia (CAH) screening project in Thailand was performed in 1999 and researchers found that the incidence was 1:19521. The incidence of CAH among newborns screened in Srinagarind Hospital was $1: 5771[15]$.

In an American retrospective cohort study, the results of screening in Texas were compared with the unscreened population of Arkansas and Oklahoma [16]. The incidence of $\mathrm{CAH}$ was similar (1: 15974 versus 1:17396).

SICKLING TEST

In our study no cases of sickle cell disease were found. The screening test can also detect other disorders affecting haemoglobin. Incidence: about 1 in every 500 African-American births and 1 in every 1,000 to 1,400 Hispanic-American births; also occurs frequently among people of Mediterranean, Middle Eastern, and South Asian descent. A higher incidence ranging from 9.2 to $22.2 \%$ has been reported from endemic areas in India [17]. A larger sample size is an ongoing program may detect known cases.

The main objective of screening is early detection and clinical intervention to prevent disabilities and also to establish the prevalence of congenital and metabolic disorders in Navi Mumbai population. The present study also helped in establishing priorities for future newborn screening in the region.

Newborn screening is dependent on close cooperation between health workers involved in sample collection, laboratory analysis and followup, diagnosis, treatment and evaluation. More public awareness is required to be generated among parents and care-givers as well.

Sociological factors have been important in the development of screening. These relevant factors are closely related to the degree of sophistication of the population at risk-for example, the level of education and awareness, the amount and form of medical care available and the general standard of living. In highly developed societies an improvement in social conditions has been accompanied by a decline in communicable disease and by an apparent or real increase in degenerative and genetically determined diseases.

Benefits of newborn screening do not end only with saving life of the diagnosed case but they extend up to prenatal period of diagnosis and family genetic counselling, thus reducing the national burden of congenital and genetic disorders. The ethical, social and legal implications must be born in mind. The challenge finally in India is the ultimate coverage of $100 \%$ screening of neonates and infants which can only be achieved with a political will and financial commitment considering our socioeconomic infrastructure.

\section{Conclusion}

In our study, the prevalence of congenital hypothyroidism was found to be 1:715, prevalence of G-6-PD deficiency was found to be $1: 89$ with higher prevalence in males as compared to females and the prevalence of congenital adrenal hyperplasia and sickle cell disease were 
zero. No cases of either congenital adrenal hyperplasia or sickle cell disease were found in our study. However over a larger sample size is an ongoing study is desirable to throw light on the actual prevalence status in the area involving all

\section{REFERENCES}

1. Therrell, BL. US newborn screening policy dilemmas for the twenty-first century.

Metab,2001;74:64-74. http://dx.doi.org/10.1006/mgme.20 01.3238

2. Dave Usha P,Das Bibhu Ranjan. Newborn Screening-from Guthrie age to Genomic age $\mathrm{j}$ Obst Gyneco India, 2010;40:210-20.

3. Laura Gru-eiro, de Papendieck, Laura Prieto et al. Congenital adrenal hyperplasia and early newborn screening: 17áhydroxyprogesterone during the first days of life Journal of Med Screen,1998;5:24-6. http://dx.doi.org/10.1136/jms.5.1.2 4

4. www.biorad.com. Biorad Laboratories (Assessed on 2015/09/20)

5. Godkar PB, Godkar PD. Special Haematological tests. In Textbook of medical laboratory technology.Ed 2;38:pp807-26.

6. International Atomic Energy Agency. Report of the East Asia Project Coordination and Planning Management Meeting, Workshop on congenital hypothyroidism: Quality assurance and validation (RAS 6/32, Tianjin, China 2002), IAEA, Vienna,2002;10-12.

7. Screening of newborn babies for congenital hypothyroidism. the hospitals handling newborn babies.

Conflict of Interest: None declared
International Atomic Energy Agency Vienna,2005;1:p13.

8. Rosenthal $M$, Addison GM, Price DA. Congenital hypothyroidism: Increased incidence in Asian families, Arch. Dis. Childhood, 1988;63:790-3. http://dx.doi.org/10.1136/adc.63.7. 790

9. Bernstein RE1, Op't Hof J Hitzeroth HW. Neonatal screening for congenital hypothyroidism. A decade's review, including South Africa. S Afr Med J,1988;73(6):33943.

10. Gurjit kaur, Jyoti S, Suksham J, Deepak C, Bir S.Chavan ,Rajiv Atwal, et al. Preliminary report on Neonatal screening for congenital hypothyroidism, congenital adrenal hyperplasia and Glucose-6phosphate dehydrogenase Deficiency: a Chandigarh experience. Indian journal of paediatric,2010;77:969-73.

11. Niazi GA, Adeyokunnu A, Westwood B, Beutler E. Neonatal jaundice in Saudi newborns with G6PD Aures. Ann Trop Paediatr, 1996;16:33-7.

12. al-Nuaim L, Talib ZA, el-Hazmi MA, Warsy AS. Sickle cell and G-6PD deficiency gene in cord blood samples: experience at King Khalid University Hospital, Riyadh. J Trop Pediatr,1997;43:71-4. http://dx.doi.org/10.1093/tropej/43 2.7

13. Nasserrulla Z, Al Jame A, Abu Srair $\mathrm{H}$, Al Qatari GS et al. Glucose-6phosphate dehydrogenase deficiency and a-thalassemia in Qatif and $\mathrm{Al}$ Has.Ann Saudi Med,1998;18:28992.

14. Hetty J van der Kamp and Jan M Wit. Neonatal screening for congenital adrenal hyperplasia. European Journal of Endocrinology,2004;151:71-5. http://dx.doi.org/10.1530/eje.0.151 U071

15. Kittiphop Somboonnithiphola, Ouyporn Panamonta et al. Newborn screening for congenital adrenal hyperplasia in Srinagarind Hospital, Khon Kaen University, Thailand. Asian Biomedicine, 2011;5:855-9.

16. Therrell BL, Johnson A and Williams D. Status of newborn screening programs in the United States,Pediatrics, 2006;117:212-52.

17. Julie Makani, Albert N Komba, Sharon E Cox, Julie Oruo, et al. Malaria in patients with sickle cell anemia: burden, risk factors, and outcome at the outpatient clinic and during hospitalization. http://dx.doi.org/10.1182/blood2009-07-233528 